\title{
Finite Element Modeling of Rock Cutting and its Fragmentation Process
}

\author{
Maria C. Jaime ${ }^{1}$, Yaneng Zhou ${ }^{3}$, Jeen-Shang $\operatorname{Lin}^{1,2^{*}}$ and Isaac K. Gamwo ${ }^{4}$ \\ ${ }^{1}$ Department of Civil and Environmental Engineering, University of Pittsburgh, Pittsburgh, PA, USA \\ ${ }^{2}$ Department of Mechanical Engineering and Material Science, University of Pittsburgh, Pittsburgh, PA, \\ USA \\ ${ }^{3}$ Department of Geosciences, Pennsylvania State University, University Park, PA, USA \\ ${ }^{4}$ U.S. Department of Energy, National Energy Technology Laboratory, Pittsburgh, PA, USA \\ * corresponding author \\ Department of Civil and Environmental Engineering \\ University of Pittsburgh, Pittsburgh, PA 15261, USA \\ jslin@pitt.edu
}

\begin{abstract}
Rock cutting is a challenging problem from a modeling perspective. The challenges come from the complexity of the physics from the tool-rock interaction to the fracture process and propagation of the quasibrittle rocks. This study was aimed at developing a finite element procedure that was capable of providing reasonable estimates of cutting forces and, at the same time, capturing the essential characteristics of the fragmentation process. Published laboratory rock scratch tests were used as modeling targets since these tests encompass all essential characteristics of rock. Both shallow cuts and deep cuts from a rectangular cutter were analyzed first, and followed by modeling of shallow cuts from a disc cutter. It was concluded that rock cutting could be reasonably modeled by using a plasticity-damage model, an element erosion scheme that remove an element when its energy release equals fracture energy, together with a proper selection of modeling parameters.
\end{abstract}

Keywords: Scratch test, rock cutting, finite element method, rock fragmentation, fracture energy 


\section{Introduction}

Even though rock cutting is at the core of all construction activities involving rocks, it remains a very difficult and challenging problem from analysis point of view. To remove rocks through cutting involves the tool-rock interaction, the fracture of rocks and the progression of fractures. The characteristics of a cutting tool, the mechanism of cutting, and the properties of the rock all impact on the process. With the limited applicability of simple analytical or approximate solutions [1-4], numerical modeling is indispensable for gaining a better understanding of the mechanics of rock cutting, to the grasp the evolution of failure, and to the provision of meaningful guides for general application. This study presents a modeling framework within the Finite Element Method (FEM) that not only provides reasonable cutting force estimates, but also captures the associated fragmentation and its progression. FEM has been employed in analyzing diverse engineering problems, and have recently been successfully applied to rock cutting and yielded useful insights $[5,6]$, but it remains a challenging task as the problem is complex and many contributing factors and their impacts remain not well understood for tackling rock cutting problems in a consistently credible manner.

The modeling difficulty can be attributed to the fact that from a modeling perspective, rock cutting poses a sequence of difficult problems: A contact problem first arises as a cutter advances and interacts with a target rock. This is followed by the problem of determining when and if the rock would fail. And if the rock does fail, a modeler is subsequently faced with the problem of how to initiate and continue on with the fragmentation process. This sequence of problems then repeats itself each step of the way until a cutting is completed. Moreover, a credible numerical model, first and foremost, should be capable of giving correct modes of failure without a priori knowledge. Depending upon the depth of cut, scratch tests are known to induce two modes of failure on rocks [7-9]. When the depth of cut is shallow, the ductile mode of failure dominates and the material failure is strength govern in which cutting proceeds almost like grinding. Its cutting force exhibits small level of fluctuation as if a rock undergoes a plastic flow. When the depth of cut is deep, the brittle mode of failure dominates and the material failure is fracture govern. Its cutting force fluctuates in large amplitudes as chips are formed and separated from the sample.

This study presents the construct of an FEM procedure in modeling rock cutting. The objectives of the study are to present a viable FEM modeling framework for rock cutting analysis. 
In the process, the issues encountered are identified, and solutions presented. In the following, the rock cutting problem of the study is defined first. This is followed by a discussion on the FEM solution strategy. Decision on a proper way to model fracture and fragmentation is then presented. Salient features of the constitutive law adopted and how the calibration was carried out are further given. Details of FEM procedure then follows. Finally an assessment of the credibility of the analysis is rendered and implications explored.

To initiate an FEM analysis, a decision first has to be made regarding how the deformation of the material is to be described. This is particularly important as a cutter induces a large deformation in rocks as it pushes through. One way to circumvent potential mesh distortion is to adopt the Euler formulation by "pushing" a material through a fixed mesh in space against a stationary cutter, and it has been shown to work for metal cutting $[10,11]$. But this approach does not work for quasibrittle materials such as rocks: For fractures are not explicitly formed but are only identified via zones of lower densities; and that chip formation follows a flow pattern that does not resemble the fragmentation of brittle rocks. A combination of Euler with Lagrange approach, or arbitrary Lagrangian-Euler method, ALE [12], also is hindered by similar problems. The study therefore adopts the updated Lagrange formulation which updates the geometry after each time step, including the new boundaries created by the use of element erosion. Also the erosion of element would cause the stiffness matrix to be singular, which is circumvented by the explicit solution scheme employed.

\section{The rock cutting problem}

The present study focuses on modeling linear orthogonal cutting of rocks as represented by laboratory rock scratch tests $[7,13]$. The selection of such a focus was decided based upon, first of all, the availability of test data. Secondly, the test encompasses all essential characteristics of rock cutting. Thirdly, the simplicity of the test makes it a perfect setting for assessing the credibility of an FEM analysis developed. Richard carried out extensive laboratory scratch tests on rocks and helped shed lights on the physics of cutting mechanics. In particular, he has carried out both deep cuts and shallow cuts, and obtained both the cutting forces and failure progression images. His data were employed as a basis for validation. However, Richard gave only the uniaxial compression strengths, $\sigma_{c}$, for rock properties and other crucial information needed for characterization was not reported. Fortunately, among the rocks he tested, the mechanical 
properties of Vosges sandstone were well documented [14], which thus facilitated a detailed study of the subset of data involving Vosges sandstone. Fig. 1 depicts a typical scratch test set up: The cutter shown has a width of $B$ and advances toward the sample at a fixed depth of cutting, $d$, slanted at a rake angle $\theta$. A slab cut denotes a cutting setup that the cutter width is no less than the sample width, $b$, and the cutting width, $w$, thus equals the sample width, $b$, and, in such cutting, the problem geometrically is two dimensional. However, a two-dimensional analysis would not yield satisfactory results for modeling a slab cut, as it would become apparent from the discussions that follow.

The mechanical specific energy, $M S E$, is defined as the mechanical energy or work required to remove a unit volume of rock. Not only that MSE is generally used to measure the efficiency of rock drilling and rock cutting, it is also an important measure in terms of the rock cutting modeling [15]:

$$
M S E=\frac{\text { Work by cutter }}{\text { Volume of cut }}
$$

In a special case, when the depth of cut is fixed, only the horizontal component of the cutting force contributes to mechanical energy of cutting. With the cutter advancing horizontally over a distance $x$, the work done by the cutter to rock is $F_{H} x$, and if the cut volume is considered as the volume swept by the cutter, which is the multiplication of cutter width, $w$, cutting depth, $d$, and the travel distance , $x$. Thus

$$
M S E=\frac{F_{H} x}{w d x}=\frac{F_{H}}{w d}
$$

where $F_{H}$ is the average horizontal cutting force over the cutter advance distance $x$.

It is clear that MSE has the unit of energy over volume such as $\mathrm{MJ} / \mathrm{m}^{3}$, but it can also be expressed in terms of stress unit, MPa, per eq. (2). For a sharp cutter, which refers to cutters that do not have a wear section, the energy is completely spent in cutting rocks and MSE, under such a condition, is referred to as the intrinsic specific energy and denoted as $\varepsilon$. Extensive tests using rectangular slab cutters have shown that $\varepsilon$ serves as a good estimate of the uniaxial compressive strength, $\sigma_{c}$, of rocks $[16,17]$. This is also the reason why MSE is frequently expressed in the stress unit. The present study modeled sharp cutters in slab cuts.

\section{Fragmentation modeling}


To capture the fracture of rocks, fracture mechanics based FEM modeling of rock cutting as a crack propagation problem has a long history [18]. As for the modeling of fragmentation, however, fragmentation involves not only crack formation, but also crack growth and chip formation. The application of fracture mechanics with explicit cracks does not work well for modeling fragmentation from rock cutting. This is mostly because the crack growth and crack interaction can easily become intractable under complex and persistent 3-dimensional loadings. Moreover, the uncertainty about the fracture process zone on the crack growth [19], and what constitute appropriate crack growth criteria [20] together introduce too many unknowns for the conventional fracture mechanics based approach to be viable.

A simple alternative to explicit crack modeling is to introduce fracture into a plasticity based continuum model, and together with an element removal scheme called element erosion in capturing the fracture initiation and growth. Within this framework, a damage index is employed to trace the level of strain softening of a quasibrittle material and determines when fracture occurs. We have investigated the use of several such models within LS-DYNA that included the Concrete Damage model, Johnson Holmquist Concrete model and the Continuous Surface Cap model [21], CSCM. We have found that the CSCM, even though developed for concrete, works best among the model investigated for rock cutting modeling, particularly for its inclusion of fracture energy as part of the material characterization. We have shown that the model was compatible with cohesive zone model for problems with known crack growth path [22], and it had been successfully used in generating Bažant's simple size-effect law [23]. A brief description of the model is herein.

CSCM encompasses the following key components: (a) a shear yield surface with kinematic hardening; (b) a hardening cap; and (c) the inclusion of different fracture mechanism. The yield surface and hardening model are common features for granular material model, but the inclusion of the strain-softening to fracture modeling further endows the model to capture rich material characteristics from the shear-enhanced compaction, shear dilatancy, post-peak softening, modulus reduction, to localized damage accumulation.

This model includes forty-five parameters, twenty-three of which are to be calibrated with laboratory triaxial compression and extension test data. In the present study we have used the triaxial test data from Vosges sandstone [14] in calibrating the yield surface and the hardening equations for the study. The yield surface and the volumetric strain-mean pressure relationship, 
from which how the hardening cap translates is defined, for the cap obtained are plotted in Figs. 2 and 3. The yield surface defines the yield shear stress in terms of the square root of the second invariant of the deviatoric stress, $J_{2}$, versus the mean pressure, or equivalently the first invariant of the stress tensor, $I_{1} / 3$, in the following form:

$$
\sqrt{J_{2}}=\alpha-\lambda \exp ^{-\beta I_{1}+I_{1}}
$$

while the mean pressure versus volume strain relationship is defined as

$$
\varepsilon_{V}=\varepsilon_{V}^{E}+W\left(1-\exp ^{\left.-D_{1}\left(I_{1}-X_{o}\right)-D_{2}\left(I_{1}-X_{o}\right)^{2}\right)}\right.
$$

where the second term on the right is the plastic volume strain.

As for the fracture modeling, the strain softening starts when the shear stress reaches the yield surface. A damage index, $d_{I}$, which is originally zero upon first reaching the yield surface, then it increases with further straining until the energy release equals the material fracture energy and $d_{I}$ becomes 1 . The fracture energy, $G_{F}$, as illustrated in Fig. 4, is related to the strain softening as follows:

$$
G_{F}=\int_{\delta_{Y}}^{\delta_{f}} \sigma d \delta=h \int_{\varepsilon_{Y}}^{\varepsilon_{f}}\left(1-d_{I}\right) \sigma_{Y} d \varepsilon
$$

where, $\sigma_{Y}$ is a yield stress, $\left(1-d_{I}\right) \sigma_{Y}$ is the softened shear stress at displacement of $\delta$, and $h$ is an finite element size. Including $h$ as part of the formulation provides regularization that reduces mesh sensitivity. An exponential model has been used to describe how the parameter d reduced as the elastic strain energy, $\tau$, increases. To avoid numerical problem, the maximum value of $d_{I}$ allowed is set as 0.99 , instead of 1 , as follows,

$$
\begin{aligned}
& d_{I}(\tau)=\frac{0.99}{A}\left\lfloor\frac{1+A}{1+A \exp ^{-C\left(\tau-\tau_{0}\right)}-1}\right\rfloor \quad \text { if } \tau>\tau_{0} \\
& =0 \quad \text { otherwise }
\end{aligned}
$$

where $\tau_{0}$ is a threshold of $\tau$ beyond which damage will accumulate; while $A$ and $C$ are two constants controlling the softening shape. The two parameters $A$ and $C$ are not independent, only $A$ is input since $G_{F}$ is also a required input. For the present study, a small $A$ from 0.1 to 0.001 works for tension fracture, whereas for compression fracture, $A=100$ was adopted. Furthermore, 
we used $35 \mathrm{Jm}^{-2}$ for $G_{F}$ in tension fracture, and $3500 \mathrm{Jm}^{-2}$ in compression fracture. Furthermore, the other parameters used for the Vosage sandstone per laboratory test results [14] are summarized in Table 1

\section{Important aspects of rock cutting modeling}

The most important aspect of rock cutting modeling is to capture the initiation of fracture and the progression of fragmentation. The initiation of fracture is determined by the level of strain softening, and the progression of fragmentation is modeled through element erosion in which an element is removed when it is fractured. On the outset, we found that it is important to carry out a 3D analysis even for slab cuts. This point would become clear when the results of analysis are discussed. Some important considerations that are crucial for the modeling efforts are discussed herein. For the present study, the rake angle was fixed at $15^{\circ}$ as adopted in the laboratory tests [7].

\subsection{Element size and type}

Element size plays a critical role in generating realistic fragmentation. In this respect, we adopted the smallest element size to be on the order of the actual particle size of Vosges sandstone. Vosges Sandstone has particle size ranges from about $0.15 \mathrm{~mm}$ to $0.45 \mathrm{~mm}$ [14]. The finest element, which was used in the area that fractures are expected, was therefore selected to be about $0.15 \mathrm{~mm}$ in size. Thus cracks generated as a result of fracture had a small size and would not distort the problem geometry.

Element erosion pattern was found to be affected by the type of element and the discretization scheme used. We found that the use of hexahedron elements, which often accompanied a discretization that resulted in a mesh of regular pattern for a prismatic rock sample. Its use would skew the fracture zone development because the regularity of the pattern of the mesh it was embedded gave regular pattern fracture. Instead, tetrahedron elements were found to provide inherent randomness through the discretization, and it gave reasonable fragmentation pattern and better force history. Thus tetrahedron elements were used.

\subsection{Contact and detection}


Contact takes place between cutter and rocks, and between the chipped rocks, and between the chipped rock and the parent rock. The imposition of non-overlapping at contacts was applied through the penalty method. Two types of contacts were present: the rock to rock contact and the rock-cutter contact.

For the cutter-rock contact, the cutter was modeled as a rigid prismatic block whose nodes were designated as the master nodes, and a window surrounding the cutter was used to define the potential slave nodes. The window moved with cutter as it advanced. This simplifies the contact detection and reduces substantially the computation time.

For the rock to rock contact, all nodes are treated as slave nodes using the "eroding single surface" contact model. In this model contacts between all parts are checked, including selfcontact. The "eroding surface" is named because it updates the surface as elements are eroded. The penalty forces were computed based on surface overlaps, which is called the component based penalty. It gives a smoother and more accurate results than point based penalty.

The contact surfaces are frictional between rocks, we specified a static coefficient of friction of 0.6 , and a dynamic coefficient of friction of 0.4. Depending upon the relative velocity among the rocks in contact, a value in between these bounds was employed in the calculation. For the cutter the interfacial friction angle lay between $18^{\circ}$ to $21^{\circ}$, and accordingly the coefficient of friction was set to 0.35 in the analysis.

\subsection{Fracture initiation and fragment formation criteria}

Element erosion allows the tracking of fractures during the rock cutting process without $a$ priori specification, nor a postulation of the direction and trajectory of fractures. When a fracture extends to a boundary, or when it joins with other existing fracture surfaces, chips are formed. The explicit FEM formulation scheme avoids the difficulty of dealing with singularity of a stiffness matrix that deteriorates because of element erosion.

When an element undergoes a substantial strain softening, i.e., its damage index, $d$, approaches 1, and it would lose nearly all its strength and stiffness. To avoid computational difficulties before fracture due to very low element stiffness, element erosion was triggered in the study when the damage index $d$ reaches 0.99. Additionally, we also required a certain level of strain be reached to avoid premature erosion, we required the maximum principal strain, $\varepsilon_{1}$, be greater than $5 \%$ in order to consider erosion; this was determined through sensitivity studies. A 
larger value of $\varepsilon_{1}$ implies that the rock is subjected to a larger deformation before breaking, which produces a larger energy release and causes fragmentation to occur more abruptly, and larger chips to form. Without this additional strain requirement, there is a tendency for elements to be eroded as soon as they came into contact with the cutter.

\subsection{Cutter advancing speed}

Laboratory scratching tests on Vosges sandstone were carried out at a speed of about $4 \times 10^{-3} \mathrm{~m} / \mathrm{s}$. Because of the high stiffness of the penalty, for convergence consideration the computation time step in the FEM was very small and was on the order of $10^{-8} \mathrm{~s}$. This made it impractical to carry out an analysis using the actual laboratory test velocity. In the present study, we have tweaked the cutting speed such that reasonable cutting forces and fragmentation speed were obtained. After extensive tuning of modeling parameters, we found that advancing the cutter at a speed $4 \mathrm{~m} / \mathrm{s}$ yielded satisfactory results.

\subsection{Rate effects}

Another parameter to adjust is the rate effect. In the continuous surface cap model, the rate effects are applied to the yield strength, and thus also affect the resulting fracture energy. The yield strength increases under a higher strain rate, $\sigma_{Y}^{R}$, is expressed as follows:

$$
\sigma_{Y}^{R}=\sigma_{Y}+E \dot{\varepsilon} \eta
$$

where $\sigma_{Y}$ is a yield strength, $E$ is Young's modulus, $\dot{\varepsilon}$ is rate of von Mises equivalent strain, $\eta$ is a stress state dependent fluidity parameter, and $E \eta$ is an equivalent viscosity. The rate effects can be considered separately for three special stress states, namely the uniaxial tensile stress state, the uniaxial compressive stress state and the pure shear stress state through selection of $\eta_{t}, \eta_{c}$ and $\eta_{s}$, respectively for $\eta$. For a general stress state, the fluidity parameter is interpolated based upon the stress invariant ratio $I_{1} / \sqrt{3 J_{2}}$. In this study, we have considered two cases: one with no rate effects, and the other with rate effects. For the latter, we set $\eta_{c}=0$ and $\eta_{s}=\eta_{t}$, with $\eta_{t}$ defined as follows, 


$$
\eta_{t}=\frac{1.2 * 10^{-4} s^{0.52}}{\dot{\varepsilon}^{0.48}}
$$

where $s$ is time, in seconds, introduced to set $\dot{\varepsilon} \eta_{t}$ dimensionless.

\section{Analysis and Results}

Two scratch tests on Vosges sandstone conducted by Richards were the target of modeling [7]. Specifically, one shallow and one deeper with depths of cut of $0.3 \mathrm{~mm}$ and 3.6 $\mathrm{mm}$, respectively, were studied. The laboratory cutting forces are duplicated in Figs. 5(a) and 5(b). It can be observed that for the shallow cut, the forces fluctuate about a mean constant value, and the cutting induced a plastic failure in the sample. As for the deeper cut, the forces exhibit some repetitive pattern in that the force would build up to a peak then drop and build up again. This is a manifest of a repeating fracture process: basically, the force builds up until a fracture is induced, and once a fracture takes place, the cutting force drops. Would the FEM procedure employed herein be able to capture these two distinct failure modes without a priori knowledge of the failure mode? These two tests thus provide an excellent base for evaluating the present study. The computed fracture and fragmentation pattern was evaluated against that recorded. As for the comparison of forces, it is noted that the forces of cutting vary substantially between samples, and the judgement of results for the shallow cut would best done through the mechanical specific energy. That is, the specific energy obtained should be close to the input uniaxial compressive strength. The laboratory test results, in this case, were slightly lower than $\sigma_{c}$ reported by Richard.

The FEM model of the rock sample had the size of $5 \mathrm{~mm}$ (width) by $38.4 \mathrm{~mm}$ (length) by $19.5 \mathrm{~mm}$ (depth) as depicted in Fig. 6. The width used in the analysis was half of the sample width used in the laboratory tests, and the forces computed, and the area used, were scaled by a factor of 2 for comparison. A fine mesh with average element size of $0.18 \mathrm{~mm}$ forms the top 6.3 $\mathrm{mm}$ of the sample, while a coarse mesh with average element size of $1.1 \mathrm{~mm}$ was used for the rest of the rock sample. The total number of nodes used was 81,276 and total number of elements was 454,870 . The cutter was represented by rigid wall that with a rake angle of 15 degrees same as that used in the tests.

The fragmentation/failure patterns from FEM results are summarized in Figs. 8 and 9, together with those recorded during the tests on Berea sandstone. The Berea sandstone tested had 
similar properties to Vosges sandstone with $\sigma_{c}$ of $39 \mathrm{MPa}, K_{I C}=0.2 \sim 0.3 \mathrm{MPa} / \mathrm{m}^{1 / 2}$ to Vosges sandstone's $\sigma_{c}$ of $28 \mathrm{MPa}, K_{I C}=0.32 \sim 0.4 \mathrm{MPa} / \mathrm{m}^{1 / 2}$ [7]. These pattern comparisons demonstrate that FEM is capable of capturing the essential characteristics of fracture and fragmentation for both the ductile and brittle failures. However, it can also be observed that immediately after an element was eroded a gap would be formed between the cutter and the remaining rock sample. This then resulted in a zero cutting force until the cutter reestablished a contact.

The forces obtained in the present study as given in Fig. 9 show very high spikes, and they are also intermittent with zero forces in-between. The computational results are not that far from those obtained from tests as the first glance would have suggested. First of all, it is important to note that the computational results were output at a rate of one point per $1.25 \times 10^{-6}$ s, or 200 points per mm of cutting; while the laboratory tests were sampled at one point per 0.01 $\mathrm{s}$, or 25 points per $\mathrm{mm}$ of cutting. Thus, a fair comparison would be to resample the analysis results. For this, we used the low pass Butterworth filter with a cutoff frequency of $1 \mathrm{kHz}$ to filter out the high frequency contents.

For the deep cuts, the value of the most interest is the mean peak force. Since fractures appear in cycles, the average peak forces at the height of fracture from each cycle are averaged. They have been used in developing the size effect law [24]. The average of the peaks from the tests was about $400 \mathrm{~N}$, and the filtered analysis results gave similar value. Thus, the deep cut analysis was deemed reasonable.

For the shallow cuts, the filtered forces become more or less constant, and are thus follow better the trend of a ductile failure mode. The filtering process did not affect the mean: the filtered forces gave a mean force of $56.6 \mathrm{~N}$, and a mechanical specific energy of $7 \mathrm{MPa}-$ which was calculated over the whole distance of cutting with the eroded volume; whereas the unfiltered forces gave almost identical results with a mean force of $56.9 \mathrm{~N}$. This computed specific energy is way lower than the input $\sigma_{c}$, and it can be attributed in part to the large number of zero forces present: if only the forces larger than $10 \%$ of the mean force were considered, the mean was raised to $84.3 \mathrm{~N}$, and the specific energy became 10.4 MPa. Even though the forces were close to those from the laboratory tests, the MSE was still much lower than the input $\sigma_{c}$. Resample analysis results, through gave better estimates of the force, failed to give the right magnitude of MSE. In the FEM model, the cutting went deeper than the bottom of the cutter and for $0.3 \mathrm{~mm}$ 
depth of cut, the volume removed below $0.3 \mathrm{~mm}$ was substantial which also led to the very low MSE obtained.

Furthermore, random or even erratic spikes are expected if the number of elements facing the cutter is small. When the number of elements participated in resisting cutting is small, the forces may rise and drop quite suddenly and show up in force spikes. Also, when few elements were used, they tended to fail and be eroded simultaneously by the advancing cutter, which then resulted in zero force gaps in the force time history as the cutter needed to advance beyond the eroded elements to make the next contact. From this consideration, one way to overcome this deficiency is to increase the width of the sample in the analysis. To test this reasoning, we more than doubled the sample width of the model from $5 \mathrm{~mm}$ to $11 \mathrm{~mm}$ in the analysis on shallow cuts that followed. However, this still did not give enough elements in the depth direction. When the shallow $0.3 \mathrm{~mm}$ depth cut was modeled, there were two layer of element in contact with the cutter at most as the smallest average element size used was $0.18 \mathrm{~mm}$.

Thus, instead of modeling such a shallow depth of cut, a deeper $0.8 \mathrm{~mm}$ depth cut was studied, which still lay within the depth of ductile mode of failure. With these considerations, further analysis was carried out of a shallow cut using a sample of $23.4 \mathrm{~mm}$ (length) by $3 \mathrm{~mm}$ (depth) by $11 \mathrm{~mm}$ (width) in size as shown in Fig 10 (a). The top $2.5 \mathrm{~mm}$ of the sample was finely discretized with an average mesh size of $0.25 \mathrm{~mm}$, and the total number of elements used in the analysis was 595,660. The analysis was carried out using the same cutting velocity and rake angle, and the cutting depth was fixed at $0.8 \mathrm{~mm}$. Through the increase in width and in depth, the zero forces gaps were gone. Still the specific energy obtained was lower than the $\sigma_{c}$ input. By further incorporating the rate effect as stated earlier, the results were improved and this compensated the effects of losing element contact with the cutter. The resulting forces so obtained are given in Fig. 10(b). The force history resembles well that shown in Fig. 5(a) obtained from laboratory tests. The spikes are less erratic, and the forces fluctuate clearly around the mean. Moreover the mechanical specific energy of the cut was found to be $1.08 \sigma_{c}$, and thus is deemed a satisfactory result.

\section{Modeling rock cutting by a PDC disc cutter}

Imposing the ductile mode of failure in rocks during cutting allows the cutting to be better controlled and be confined within a specified area. Thus it is desirable in many applications that 
such as oil drilling. An analysis of the cutting action of a single PDC (polycrystalline diamond compact) cutter is therefore presented here. PDC, drill bits are fixed bits with no moving parts, commonly used in oil well drilling, cut the rocks though the PDC cutters mounted on the bit body. The diameter and thickness of the PDC disc cutter considered was $13 \mathrm{~mm}$ and $2 \mathrm{~mm}$, respectively. The rake angle of the disc cutter was $15^{\circ}$. Here the problem setup was as follows: A sharp PDC disc cutter advanced into a slab of Vosges sandstone with both horizontal and vertical velocities. The slab rock model was the same as that used in slab cutting. The cutter advanced with the same horizontal velocity as before at $4 \mathrm{~m} / \mathrm{s}$, while the vertical velocity of cutter was introduced at a fixed $0.255 \mathrm{~m} / \mathrm{s}$ so that the cutting depth would increase linearly with time from 0 on the left to $1.5 \mathrm{~mm}$ on the right. At the maximum cutting depth of $1.5 \mathrm{~mm}$, the cutting width was $8.4 \mathrm{~mm}$. We have kept a margin of at least five element-sizes beyond immediate contact area in the lateral direction to avoid boundary effect.

The cutting forces versus cutting depths obtained are presented in Fig. 11 (b). It shows that the vertical component of the cutting forces was much smaller than the horizontal component. Notice that the cutting depth here refers to the depth of the tip of the disc cutter. Unlike the cases involving rectangular cutters, here the depth of cutting was not fixed across the cross section but had the maximum value at the tip and reduced gradually to zero at the edge. When the maximum depth reached was at $1.5 \mathrm{~mm}$, the corresponding average depth of cut was $1.01 \mathrm{~mm}$, and thus remained essentially within the domain of ductile failure mode. Also, in this setup, the specific energy, MSE, had contribution from the vertical force but that turned out to be negligible as both the vertical velocity and the vertical forces obtained were small. For the assessment of the results, the cutting pattern was shown to be that of shallow cuts as can be observed in Fig. 11 (a), and the forces from the energy viewpoint was also reasonable: Using the actual volume being cut in defining the MSE, the FEM computation, after initial higher values, had the specific energy fluctuated around $40.2 \mathrm{MPa}$, or $1.03 \sigma_{c}$ as shown in Fig. 11 (c). This basically reaffirms that for sharp cutters the specific energy is equal approximately to $\sigma_{c}$, and that it could serve as a basis for interpreting drilling mechanics [25].

\section{Conclusions}


A procedure and its calibration were presented on how to model a rock cutting using FEM. Of particular interests are that the study demonstrated a workable strategy of combining the continuum plasticity damage mechanics with the element erosion scheme. Both the fragmentation process and the cutting forces obtained were deemed reasonable. It is conceivable that resolution of the study could be improved somewhat with further tuning, but we do not expect that to provide significant enhancement from what were shown. This study also modeled the cutting by a single PDC cutter, and the results showed that within the shallow depth of cutting with sharp cutters, the $M S E$ also related well to the uniaxial compressive strength of rocks.

We believe the present work lays a foundation for further development. How to scale up the present study from modeling laboratory tests to problems of engineering applications is an outstanding issue that needs further investigation. The present procedure employs small element size, on the order of rock particle size, in order to capture the details of rock fragmentation process. Using particle size element is no way for scaling up for problems of scale as the computational cost would be formidable. It is possible that capturing such details may not be necessary in terms of applications. In this case, one might implement a nonlocal constitutive model so as to employ elements of larger sizes. A readily available solution would be to use adaptive meshing, and that refined mesh is updated only within the evolving zones of active toolrock interaction.

\section{Acknowledgements}

This technical effort was performed in support of the research on drilling under extreme conditions under the RDS contract DE-AC26-04NT41817 between the Department of Energy's National Energy Technology Laboratory and the University of Pittsburgh. The authors would also like to expresses their gratitude to Emmanuel Detournay of the University of Minnesota for providing the cutting films, and to Pierre Bésuelle of the National Center for Scientific Research, France, for providing the Vosges sandstone testing data. 


\section{References}

[1] Merchant ME. Mechanics of the metal cutting process, I: orthogonal cutting. J Appl Phys 1945 $16: 267-75$.

[2] Merchant ME. Mechanics of the metal cutting process. II. plasticity conditions in orthogonal cutting. J Appl Phys 1945;16:318-24.

[3] Nishimatsu Y. The mechanics of rock cutting. Int J Rock Mech Min Sci Geomech Abstr 1972;9:26170 .

[4] Molinari A, Moufki A. The Merchant's model of orthogonal cutting revisited: A new insight into the modeling of chip formation. Int J Mech Sci 2008;50:124-31.

[5] Menezes PL, Lovell MR, Avdeev IV, Higgs Iii CF. Studies on the formation of discontinuous rock fragments during cutting operation. Int J Rock Mech Min Sci 2014;71:131-42.

[6] Menezes PL, Lovell MR, Avdeev IV, Lin J-S, Higgs III CF. Studies on the formation of discontinuous chips during rock cutting using an explicit finite element model. Int J Adv Manufact Tech 2014;70:63548 .

[7] Richard T. Determination of rock strength from cutting tests. MS thesis, University of Minnesota, 1999.

[8] Chaput E. Observation and analysis of hard rocks cutting failure mechanisms using PDC cutters. PhD Thesis, Imperial College London, 1991.

[9] Nicodeme P. Transition between ductile and brittle mode in rock cutting. Rapport de stage d'option scientifique: Ecole Polytechnique; 1997.

[10] Raczy A, Elmadagli M, Altenhof WJ, Alpas AT. An eulerian finite-element model for determination of deformation state of a copper subjected to orthogonal cutting. Metall Mater Trans A 2004;35:2393-400.

[11] Elmadagli M, Alpas AT. Metallographic analysis of the deformation microstructure of copper subjected to orthogonal cutting. Mater Sci Eng A 2003;355:249-59.

[12] Belytschko T, Liu WK, Moran B, Elkhodary K. Nonlinear finite elements for continua and structures. London: Wiley; 2013.

[13] Schei G, Fjær E, Detournay E, Kenter C, Fuh G, Zausa F. The scratch test: an attractive technique for determining strength and Elastic properties of sedimentary rocks. In: Proc SPE Annual Technical Conference and Exhibition, 2000.

[14] Bésuelle P, Desrues J, Raynaud S. Experimental characterisation of the localisation phenomenon inside a Vosges sandstone in a triaxial cell. Int J Rock Mech Min Sci 2000;37:1223-37.

[15] Detournay E, Defourny P. A phenomenological model for the drilling action of drag bits. Int J Rock Mech Min Sci 1992;29:13-23.

[16] Richard T, Dagrain F, Poyol E, Detournay E. Rock strength determination from scratch tests. Eng Geol 2012;147-148:91-100. 
[17] Richard T, Detournay E, Drescher A, Nicodeme O, Fourmaintraux D. The scratch test as a means to measure strength of sedimentary rocks. In: Proc SPE/ISRM Rock Mechanics in Petroleum Eng Conference, Trondheim, Norway, 1998. p. 15-22.

[18] Ingraffea AR. Theory of crack initiation and propagation in rock. In: Fracture Mechanics of Rock, New York: Academic Press, 1987, pp. 71-110.

[19] Bažant ZP, Planas J. Fracture and size effect in concrete and other quasibrittle materials. Boca Raton: CRC Press; 1997.

[20] da Silva BG, Einstein HH. Modeling of crack initiation, propagation and coalescence in rocks. Int J Fract 2013;182:167-86.

[21] Murray YD. User manual for LS-DYNA concrete material model 159. Mclean: U.S. Department of transportation, Federal Highway Administration 2007.

[22] Zhou Y, Lin J-S. Modeling fracture of quasibrittle materials: a comparative study. In: Proc 47th US Rock Mechanics Symposium, San Francisco, 2013.

[23] Zhou Y, Lin J-S. Modeling the ductile-brittle failure mode transition in rock cutting. Eng Fract Mech 2014;127:135-47.

[24] Zhou Y, Lin J-S. On the critical failure mode transition depth for rock cutting. Int J Rock Mech Min Sci 2013;62:131-7.

[25] Detournay E, Richard T, Shepherd M. Drilling response of drag bits: theory and experiment. Int J Rock Mech Min Sci 2008;45:1347-60. 


\section{List of Tables}

Table 1 A summary of key parameters for the modeling of Cutting Vosges Sandstone 


\section{List of Figures}

Figure 1 Layout of a scratch test

Figure 2 The yield surface and hardening cap fitted for Vosges sandstone

Figure 3 The mean pressure-volumetric strain relationship fitted for Vosges sandstone

Figure 4 The softening curve, damage index and the Fracture energy $G_{F}$

Figure 5 Laboratory scratch test on Vosges tests (a) a shallow cut with $d=0.3 \mathrm{~mm}$ (b) a deeper cut with $d=3.6 \mathrm{~mm}$

Figure 6 FEM model for slab scratch tests (a) layout (2) FEM mesh (c) two mesh zones used

Figure 7 A comparison of failure/fragmentation pattern for shallow cut, $d=0.3 \mathrm{~mm}$. On the left: FEM results on Vosges sandstone; on the right, laboratory tests of Berea sandstone.

Figure 8 A comparison of failure/fragmentation pattern for the deeper cut. On the left: FEM results on Vosges sandstone, $d=3.6 \mathrm{~mm}$ w.r.t cutter advances; on the right, laboratory tests of Berea sandstone, $d=4 \mathrm{~mm}$

Figure 9 A frontal view of the cutting showing the damage state in front of the cutter

Figure 10 Unfiltered and filtered forces from FEM analysis on Vosges Sandstone (a) $d=0.3 \mathrm{~mm}$ (b) $d=3.6 \mathrm{~mm}$

Figure 11 A refined shallow cut model (a) A snapshot of the failure/fragmentation pattern (b) The computed cutting forces

Figure 12 A linear orthogonal cut model for a PDC cutter (a) A snapshot of the failure/fragmentation pattern (b) The computed cutting forces (c) the computed mechanical specific energy of cutting 
Table 1 Key material parameters calibrated through experiment data [14]

\begin{tabular}{|c|c|c|c|c|c|c|c|c|c|c|c|}
\hline \multirow{2}{*}{$\begin{array}{c}\text { Young's } \\
\text { Modulus } \\
E \\
(\mathrm{GPa})\end{array}$} & \multirow{2}{*}{$\begin{array}{c}\text { Poisson } \\
\text { Ratio } \\
\\
\qquad\end{array}$} & \multirow{2}{*}{$\begin{array}{c}\text { Uniaxial } \\
\text { Compressive } \\
\text { Strength } \\
\sigma_{c} \\
(\mathrm{MPa})\end{array}$} & \multirow{2}{*}{$\begin{array}{c}\text { Tensile } \\
\text { Strength } \\
\sigma_{t}\end{array}$} & \multicolumn{3}{|c|}{ Yield surface parameters } & \multicolumn{5}{|c|}{ Plastic volume strain parameters } \\
\hline & & & & $\begin{array}{c}\alpha \\
(\mathrm{MPa})\end{array}$ & $\begin{array}{c}\lambda \\
(\mathrm{MPa})\end{array}$ & $\begin{array}{c}\beta \\
\left(\mathrm{MPa}^{-1}\right)\end{array}$ & $\gamma$ & $\mathrm{W}$ & $\begin{array}{c}\mathrm{D}_{1} \\
\left(\mathrm{MPa}^{-1}\right)\end{array}$ & $\begin{array}{c}\mathrm{D}_{2} \\
\left(\mathrm{MPa}^{-2}\right)\end{array}$ & $\begin{array}{c}\text { Хo } \\
\text { (MPa) }\end{array}$ \\
\hline 8.3 & 0.3 & 38.7 & 2.9 & 75.0 & 70.0 & $8.0 \mathrm{e}-3$ & $1.0 \mathrm{e}-4$ & $7.8 \mathrm{e}-3$ & $3.9 \mathrm{e}-2$ & $1.0 \mathrm{e}-5$ & 3.0 \\
\hline
\end{tabular}




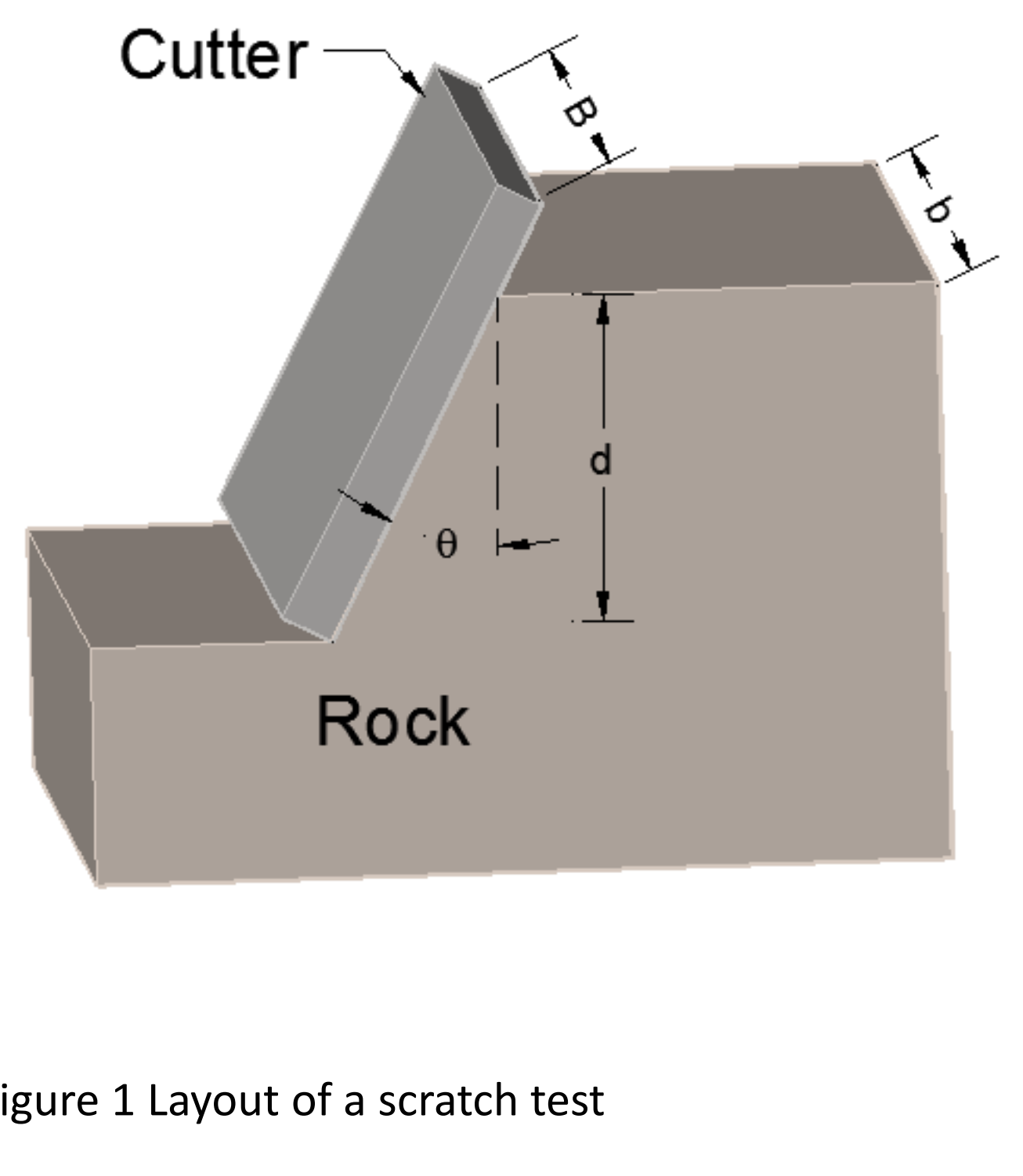

Figure 1 Layout of a scratch test

\section{Cutter}

\section{Rock}

Figure 1 Layout of a scratch test

Figure

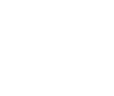




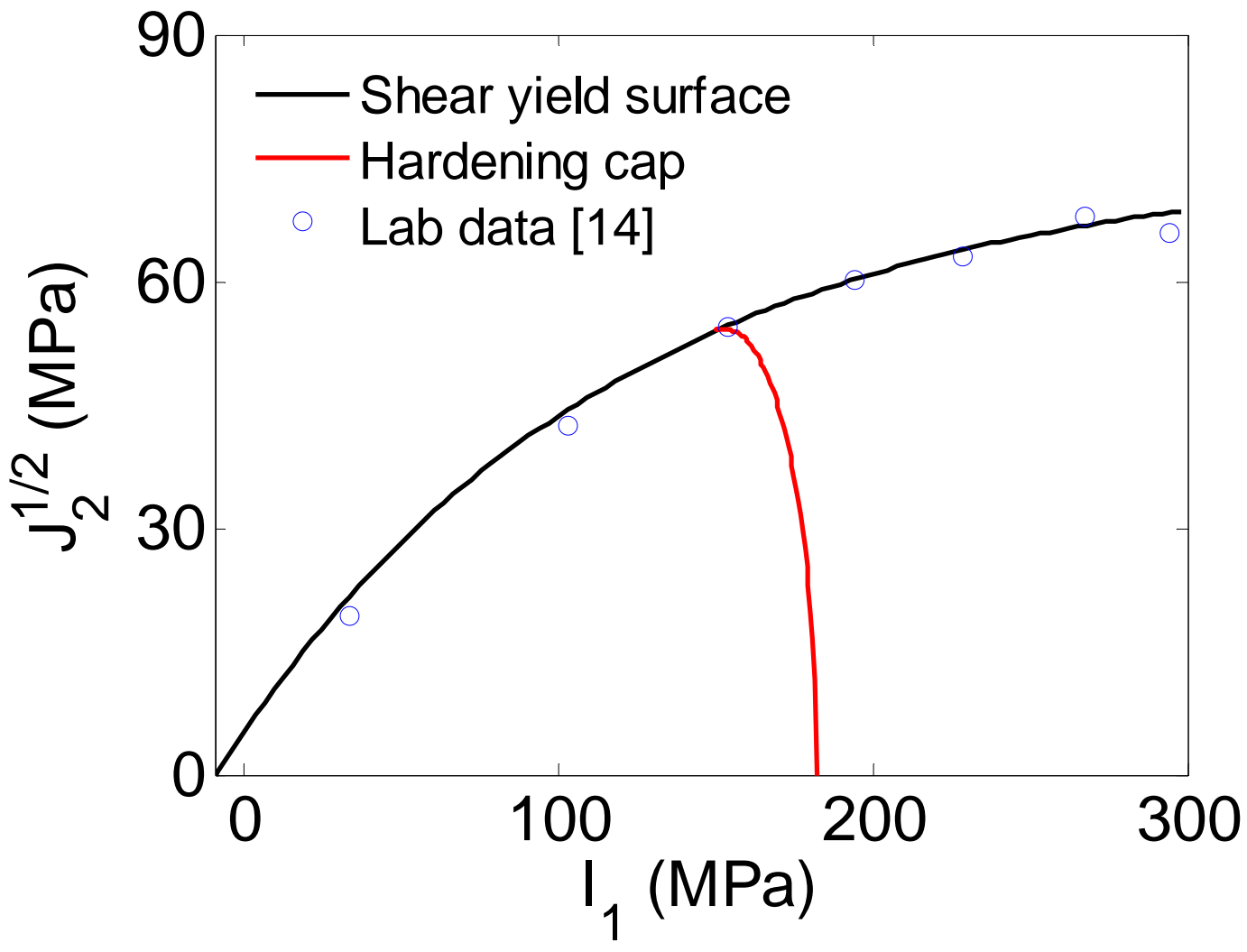

Figure 2 The yield surface and hardening cap fitted for Vosges sandstone 


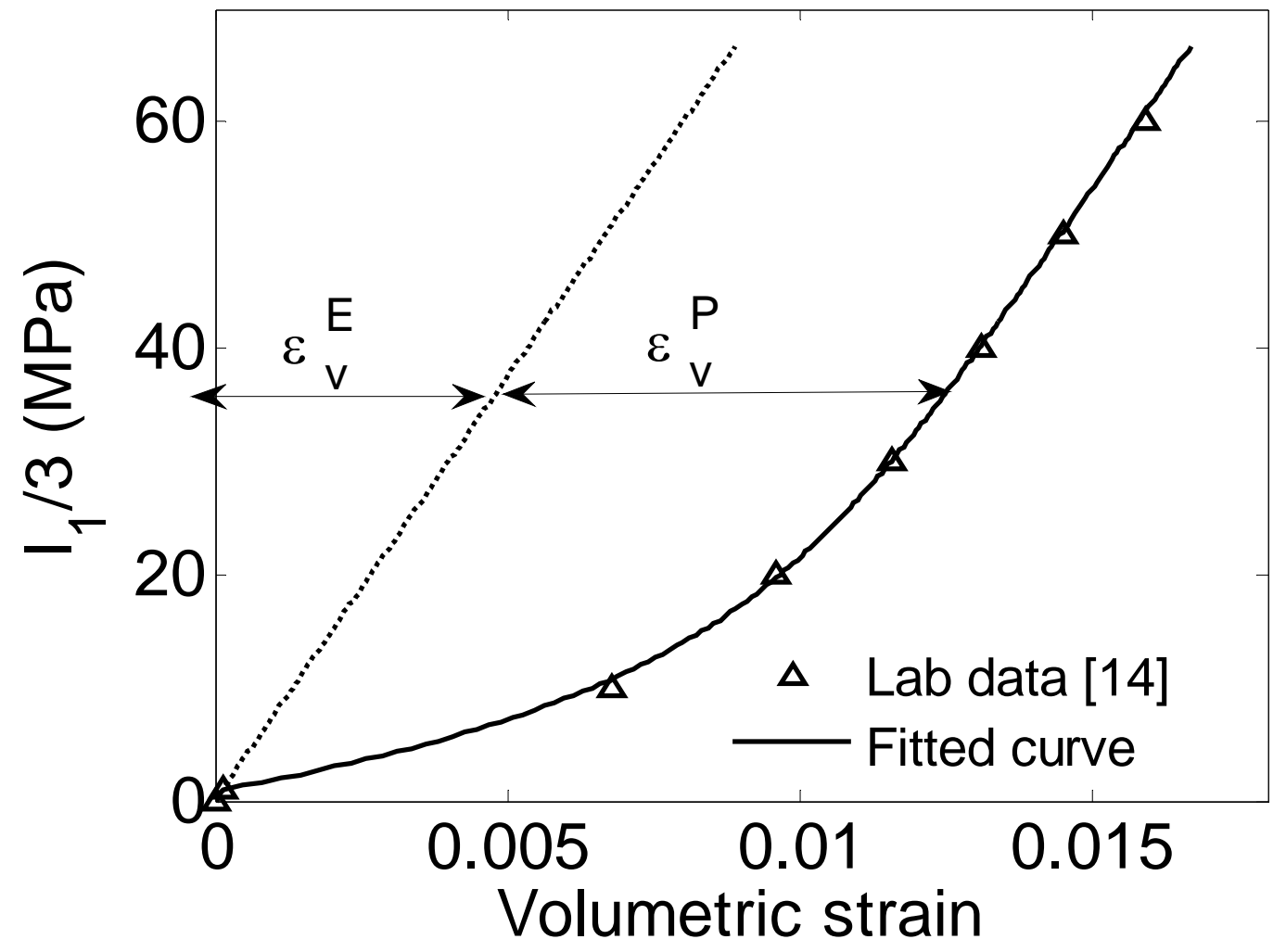

Figure 3 The mean pressure-volumetric strain relationship fitted for Vosges sandstone 


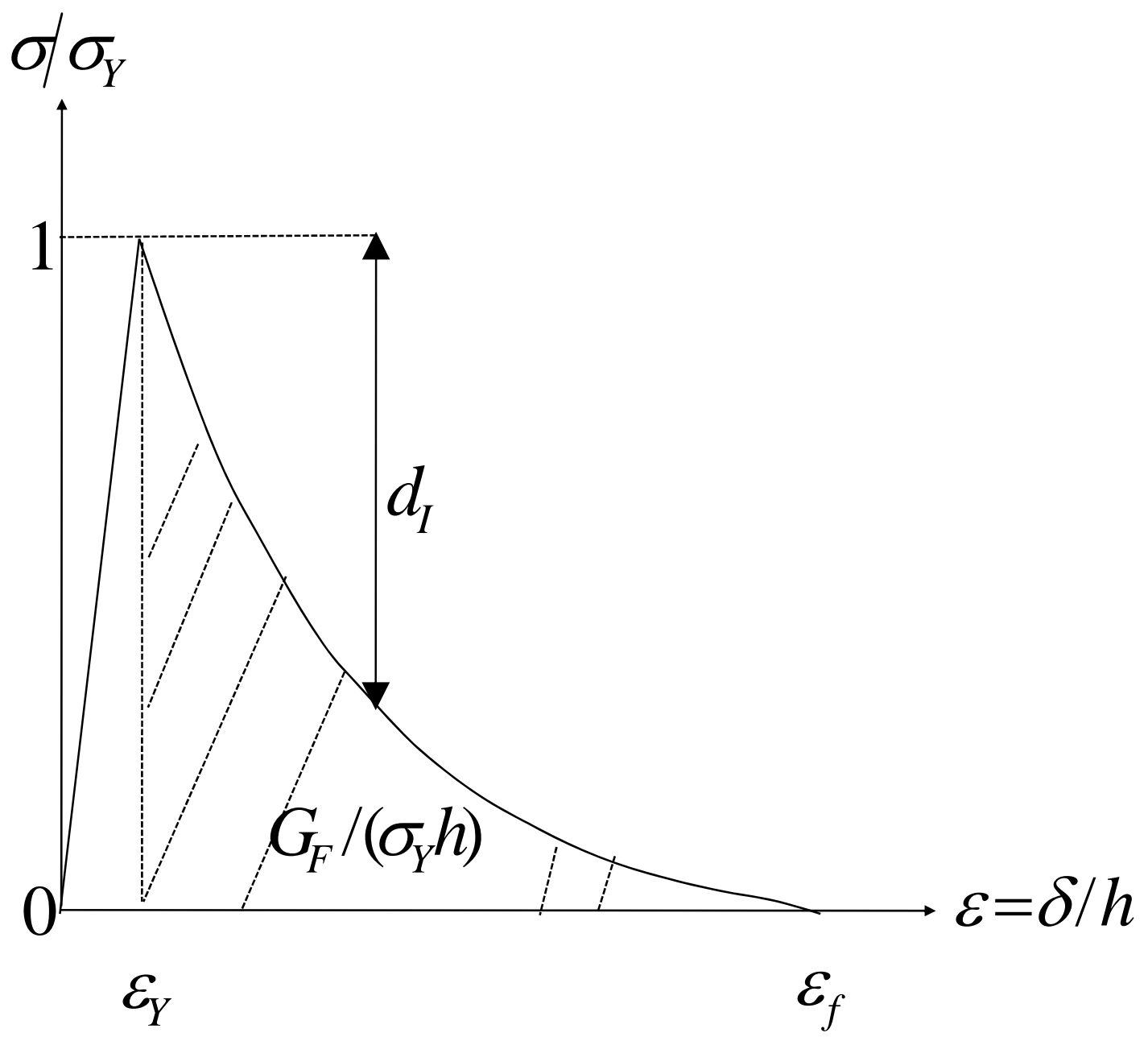

Figure 4 The softening curve, damage index and the Fracture energy $\mathrm{G}_{\mathrm{F}}$ 


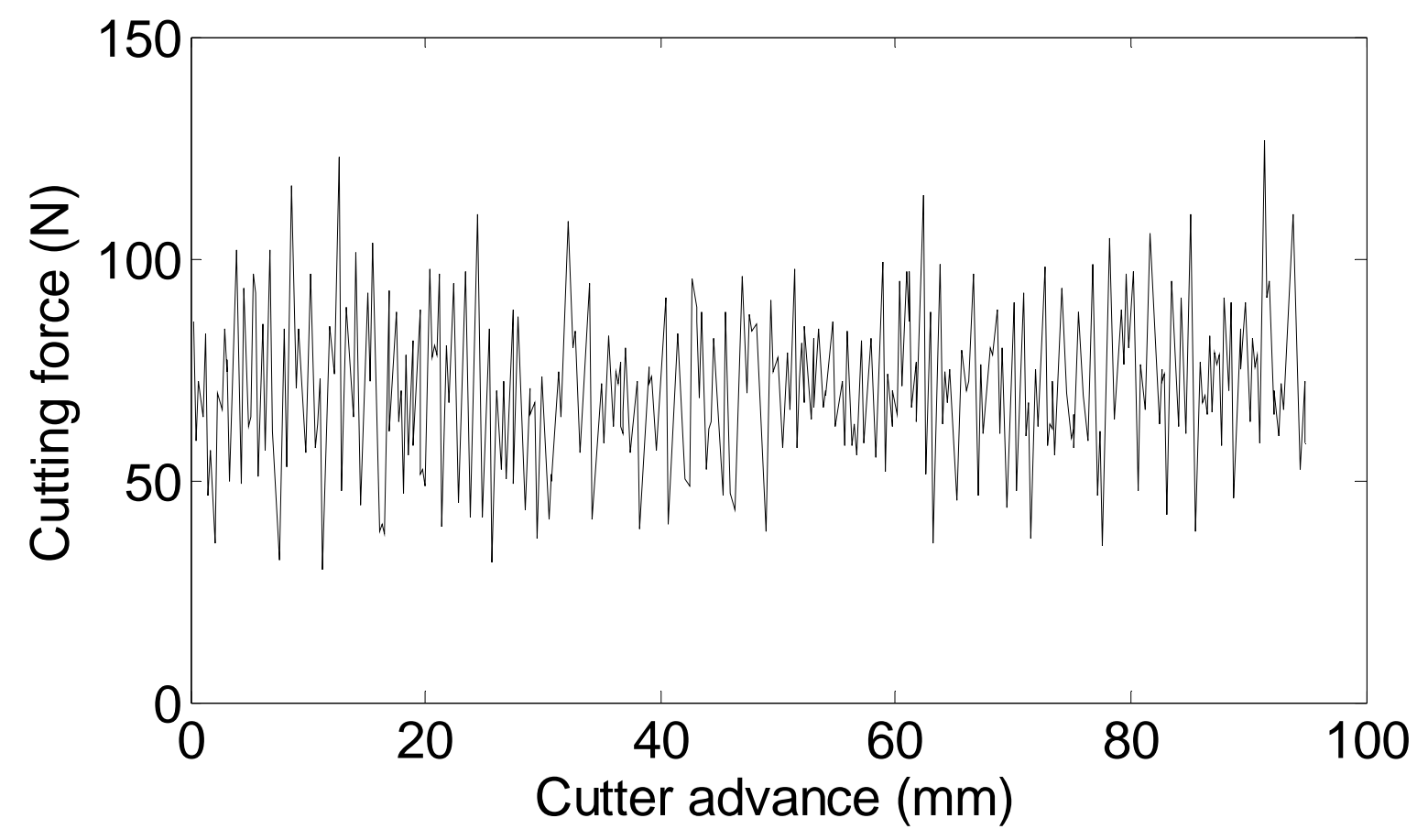

a) a shallow cut with $\mathrm{d}=0.3 \mathrm{~mm}$

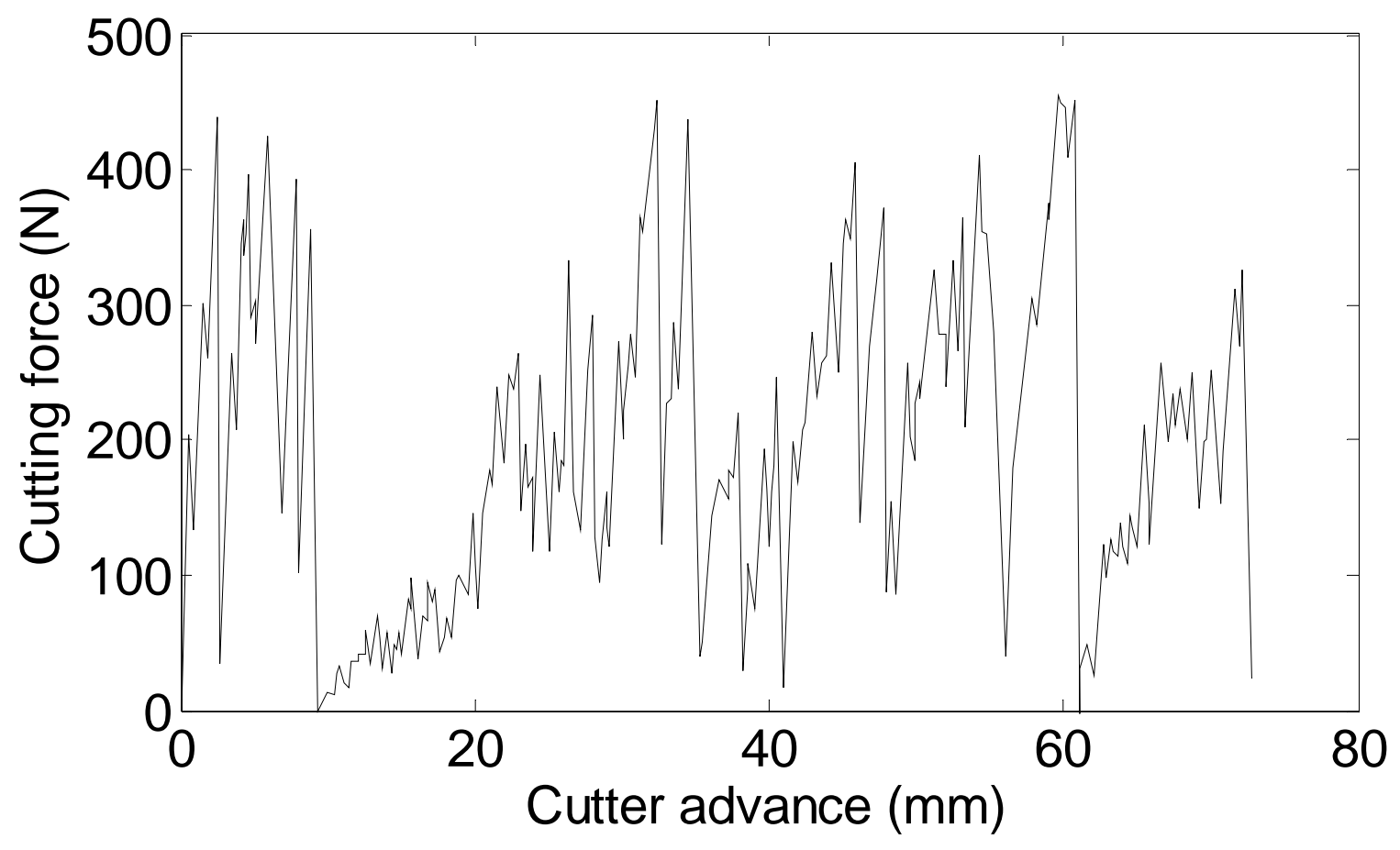

(b) a deeper cut with $\mathrm{d}=3.6 \mathrm{~mm}$

Figure 5 Laboratory scratch test on Vosges tests (a) a shallow cut with $d=0.3 \mathrm{~mm}(\mathrm{~b})$ a deeper cut with $\mathrm{d}=3.6$ $\mathrm{mm}$ 

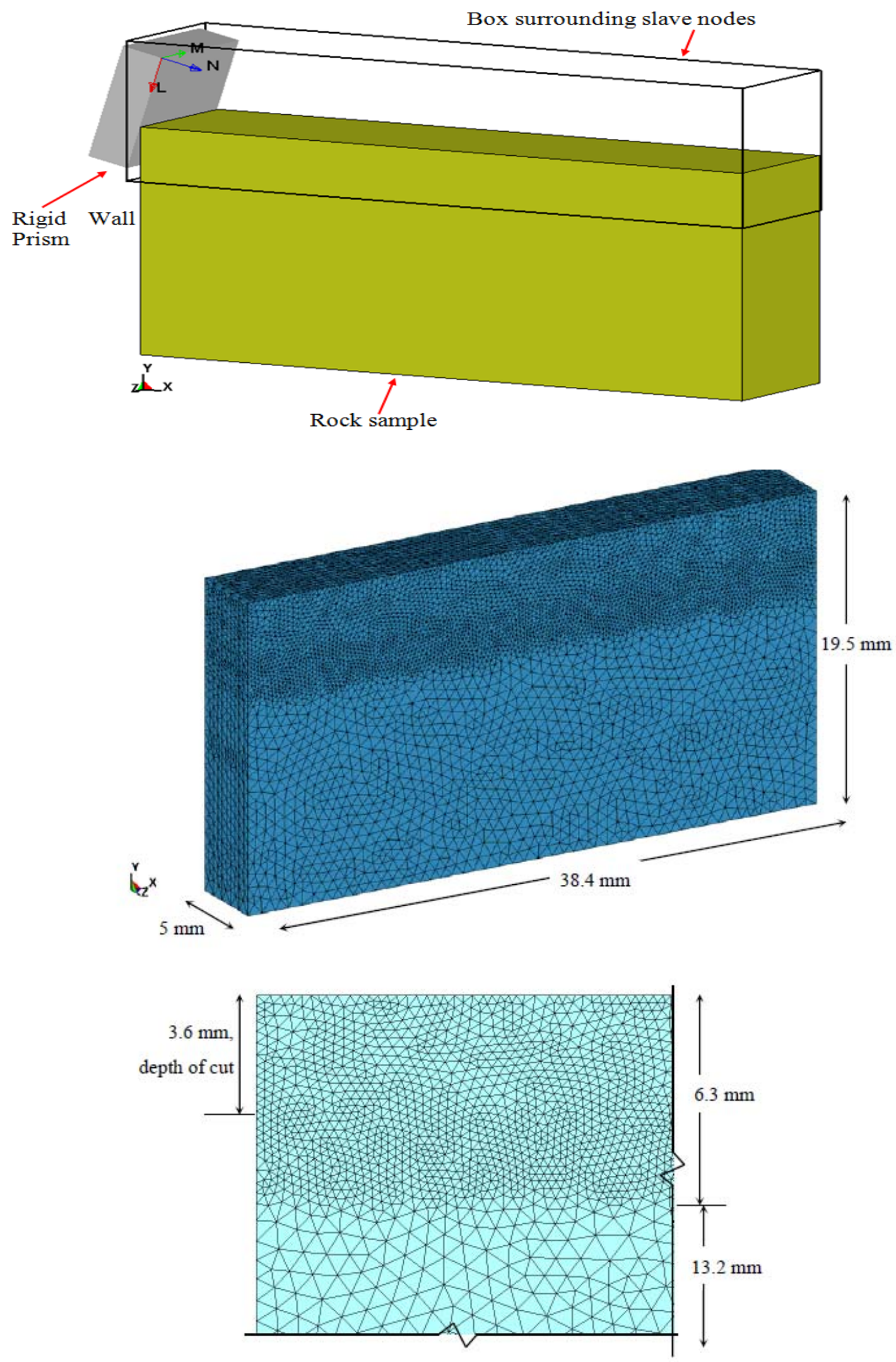

Figure 6 FEM model for slab scratch tests (a) layout (2) FEM mesh (c) two mesh zones used 


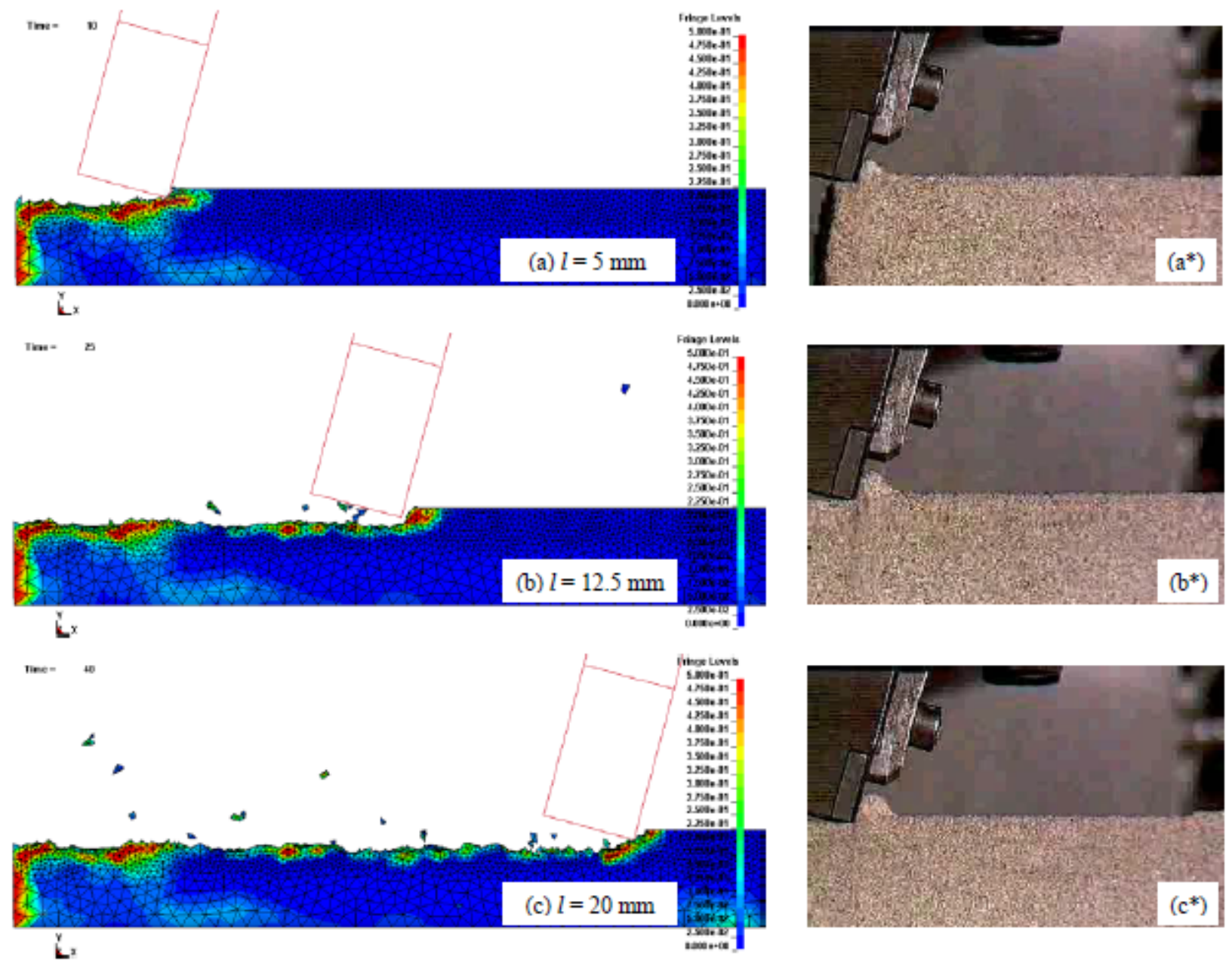

Figure 7 A comparison of failure/fragmentation pattern for shallow cut, $d=0.3 \mathrm{~mm}$. On the left: FEM results on Vosges sandstone; on the right, laboratory tests of Berea sandstone. 


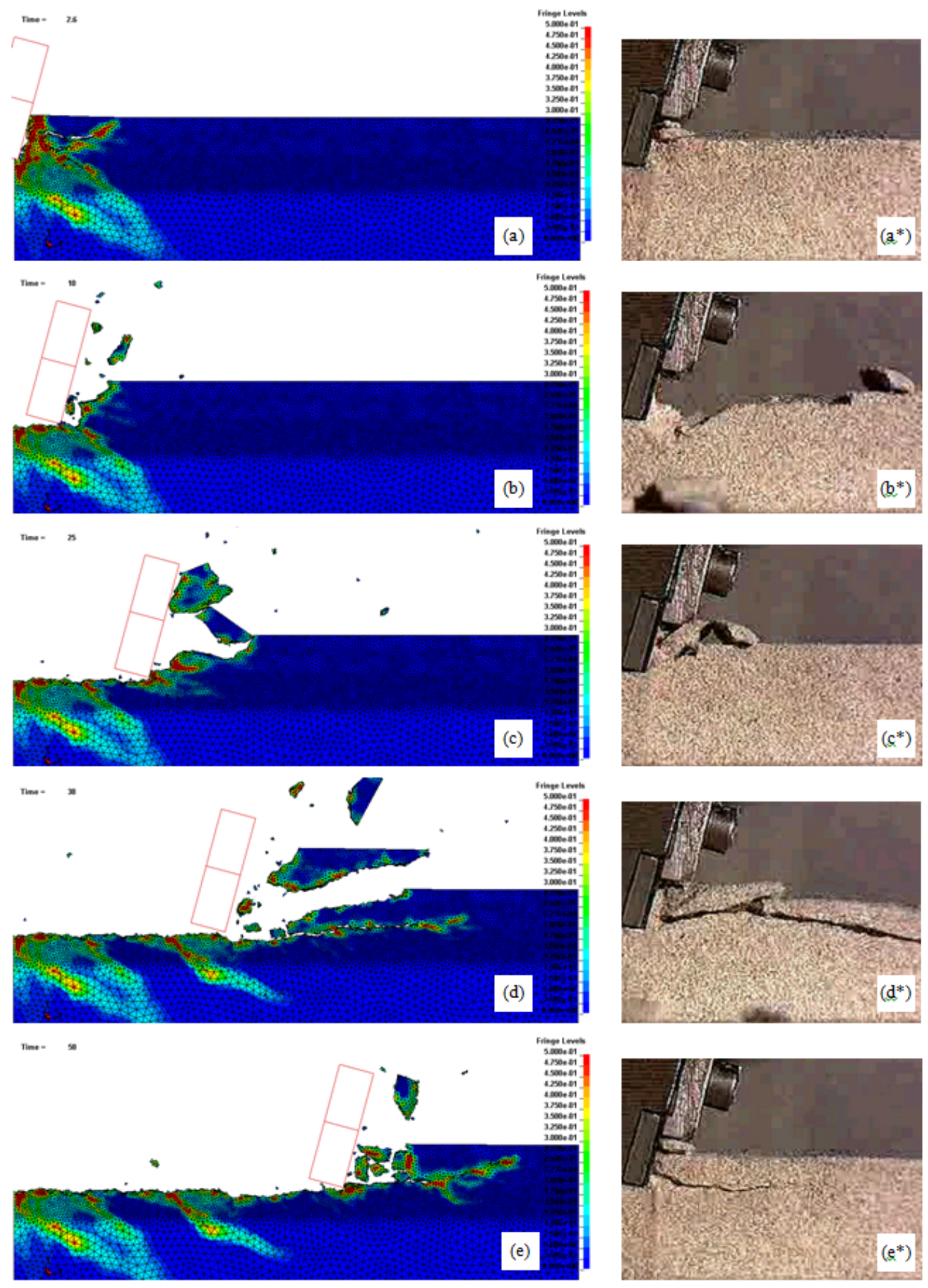

Figure 8 A comparison of failure/fragmentation pattern for the deeper cut. On the left: FEM results on Vosges sandstone, $d=3.6 \mathrm{~mm}$ w.r.t cutter advances; on the right, laboratory tests of Berea sandstone, $d=4 \mathrm{~mm}$ 


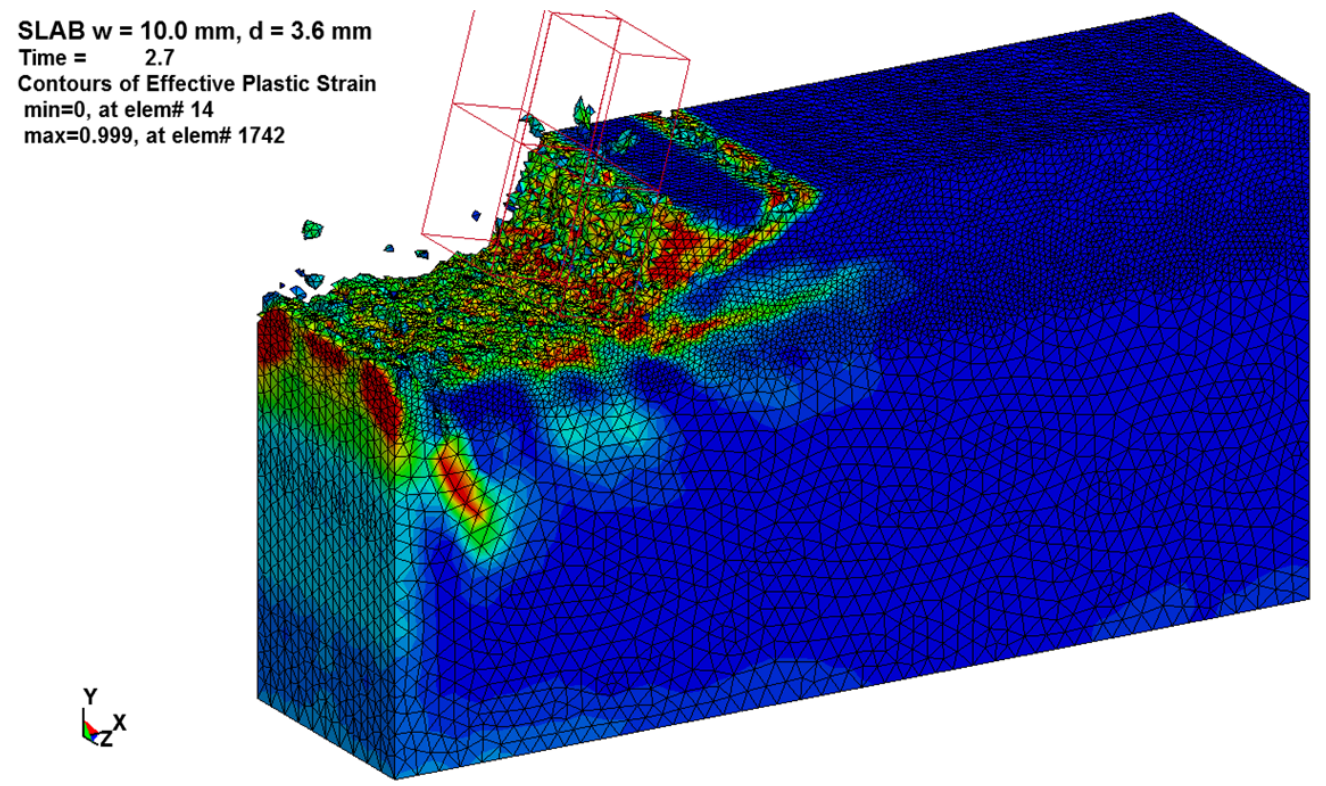

Figure $9 \mathrm{~A}$ frontal view of the cutting showing the damage state in front of the cutter 


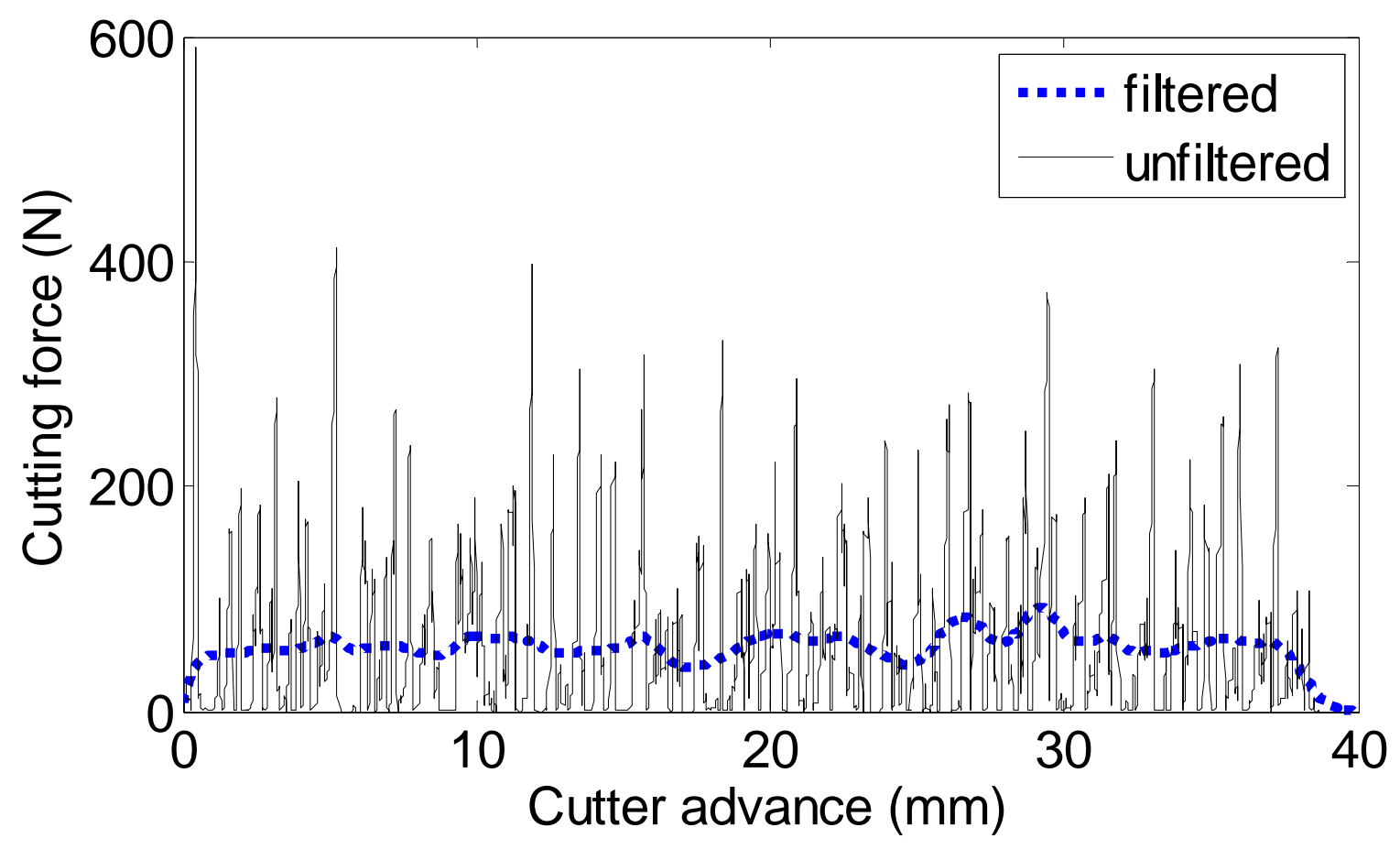

(a) $\mathrm{d}=0.3 \mathrm{~mm}$

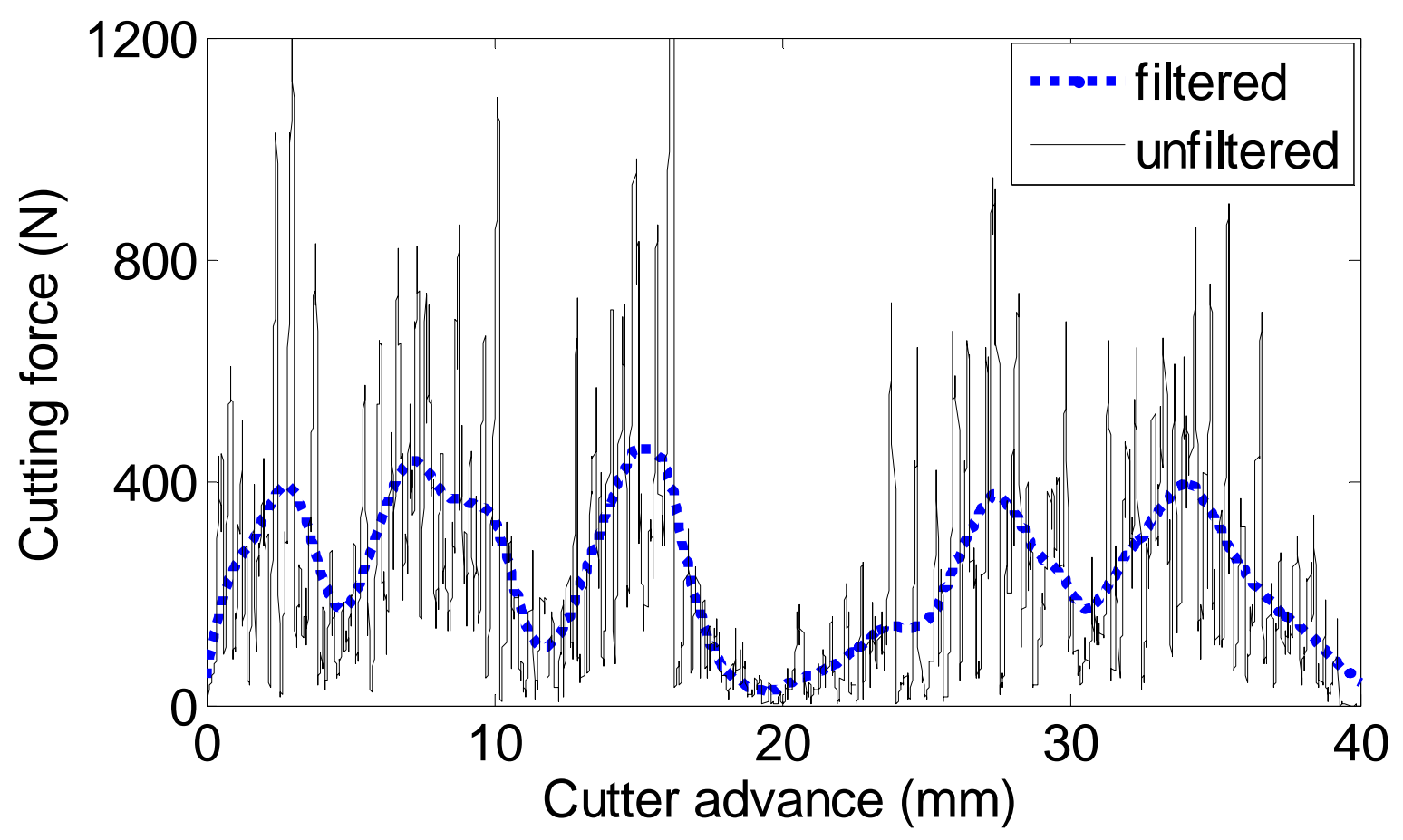

(b) $\mathrm{d}=3.6 \mathrm{~mm}$

Figure 10 Unfiltered and filtered forces from FEM analysis on Vosges Sandstone (a) $d=0.3 \mathrm{~mm}$ (b) $d=3.6$ $\mathrm{mm}$ 


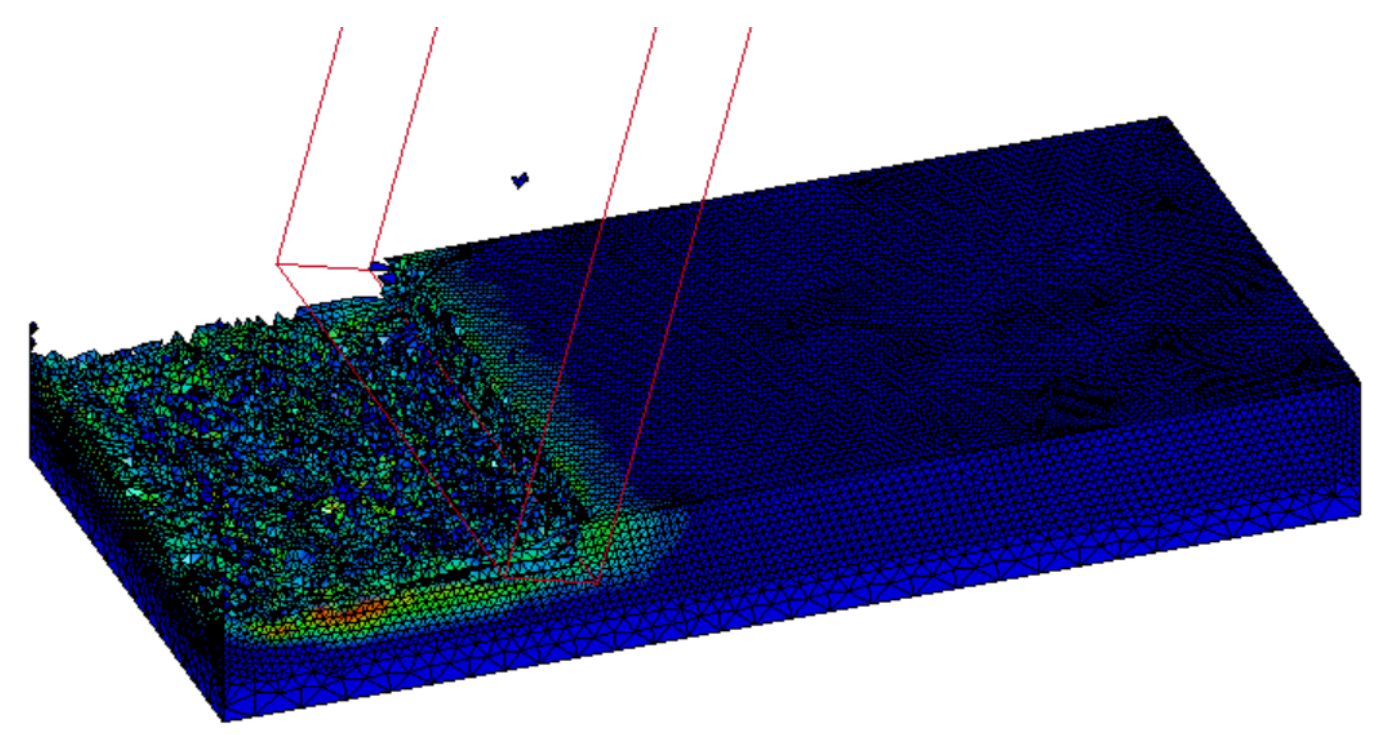

(a) A snapshot of the failure/fragmentation pattern

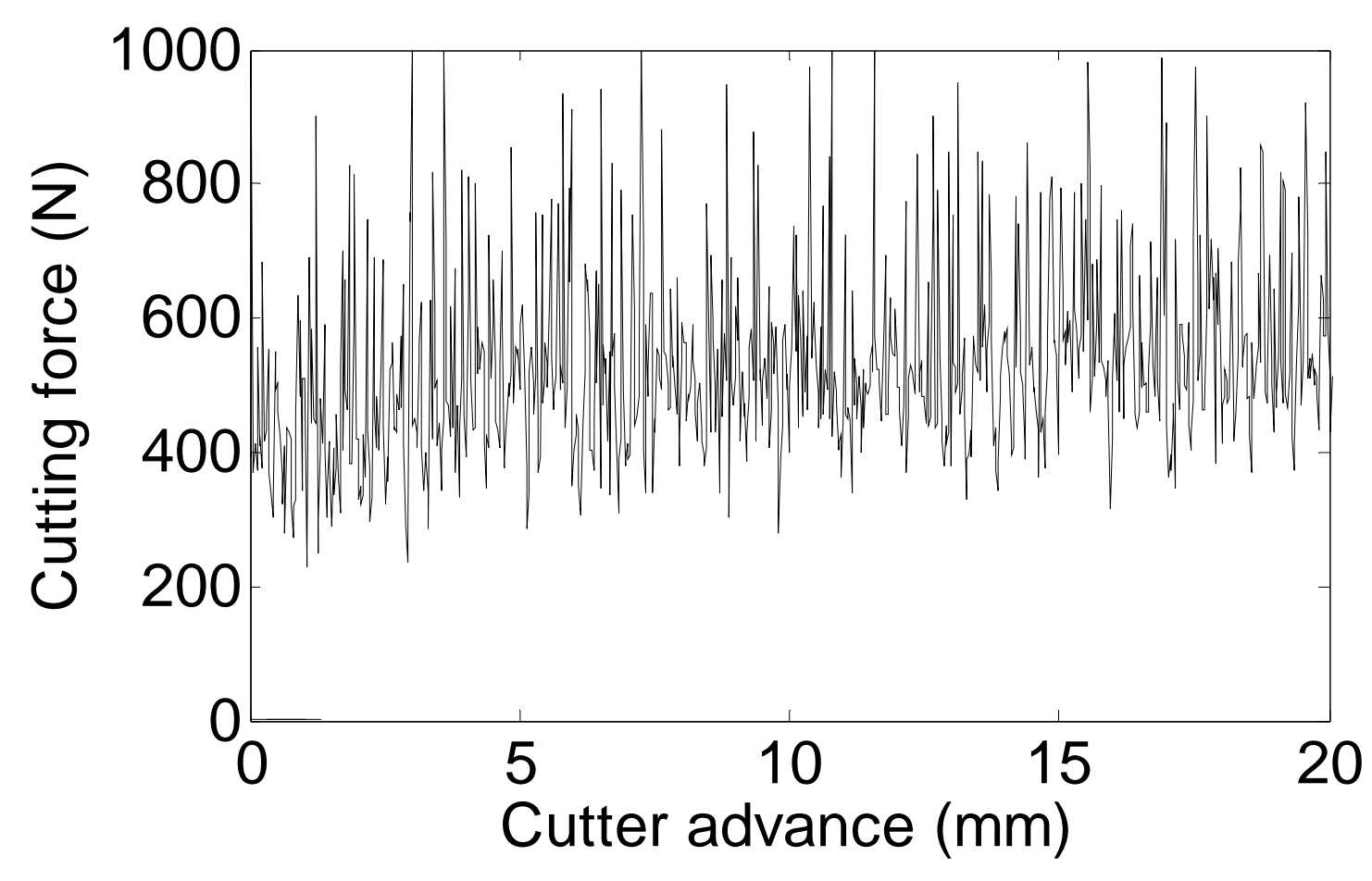

(b) The computed cutting forces.

Figure 11 A refined shallow cut model (a) A snapshot of the failure/fragmentation pattern (b) The computed cutting forces. 


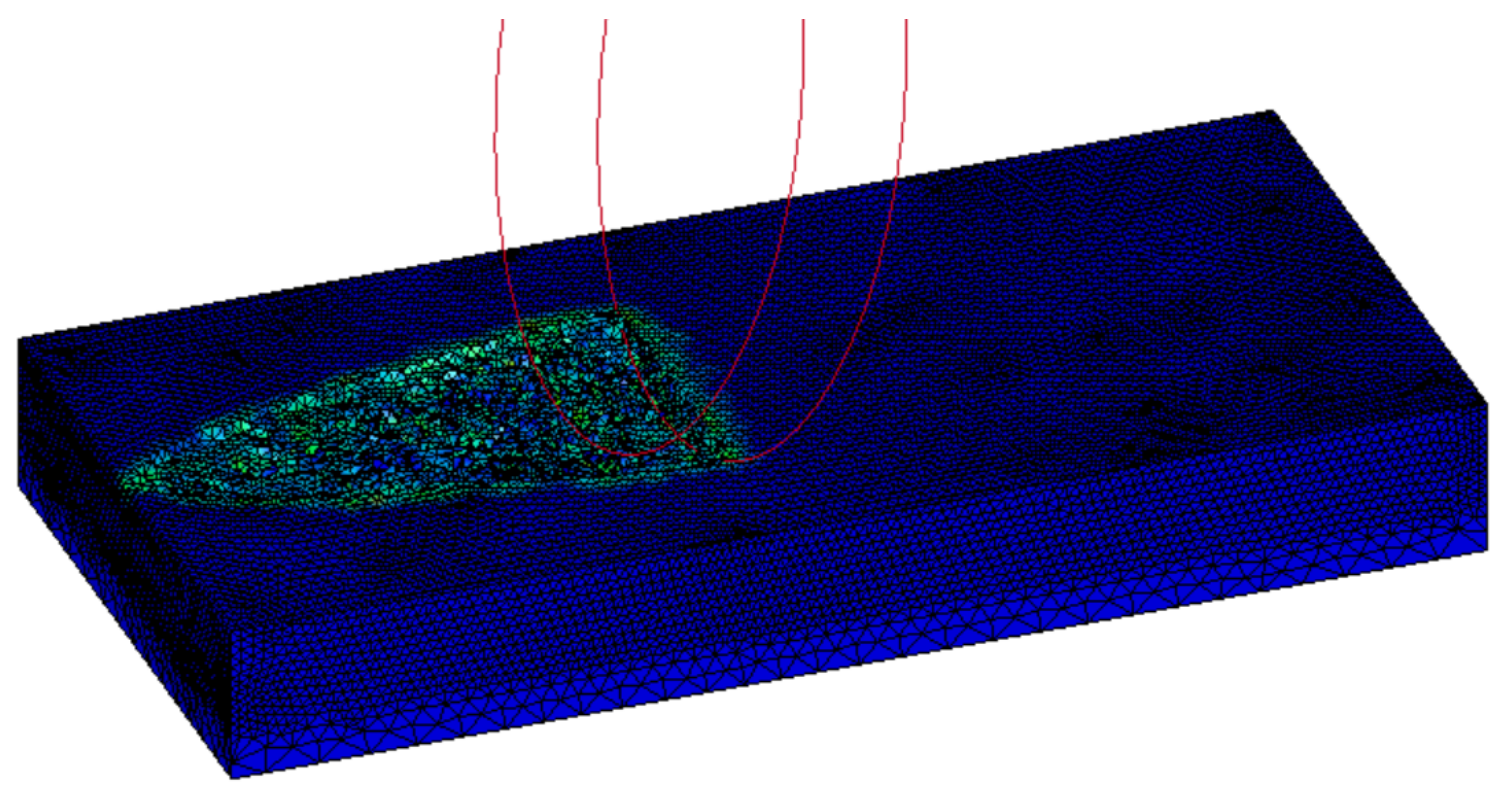

(a) A snapshot of the failure/fragmentation pattern

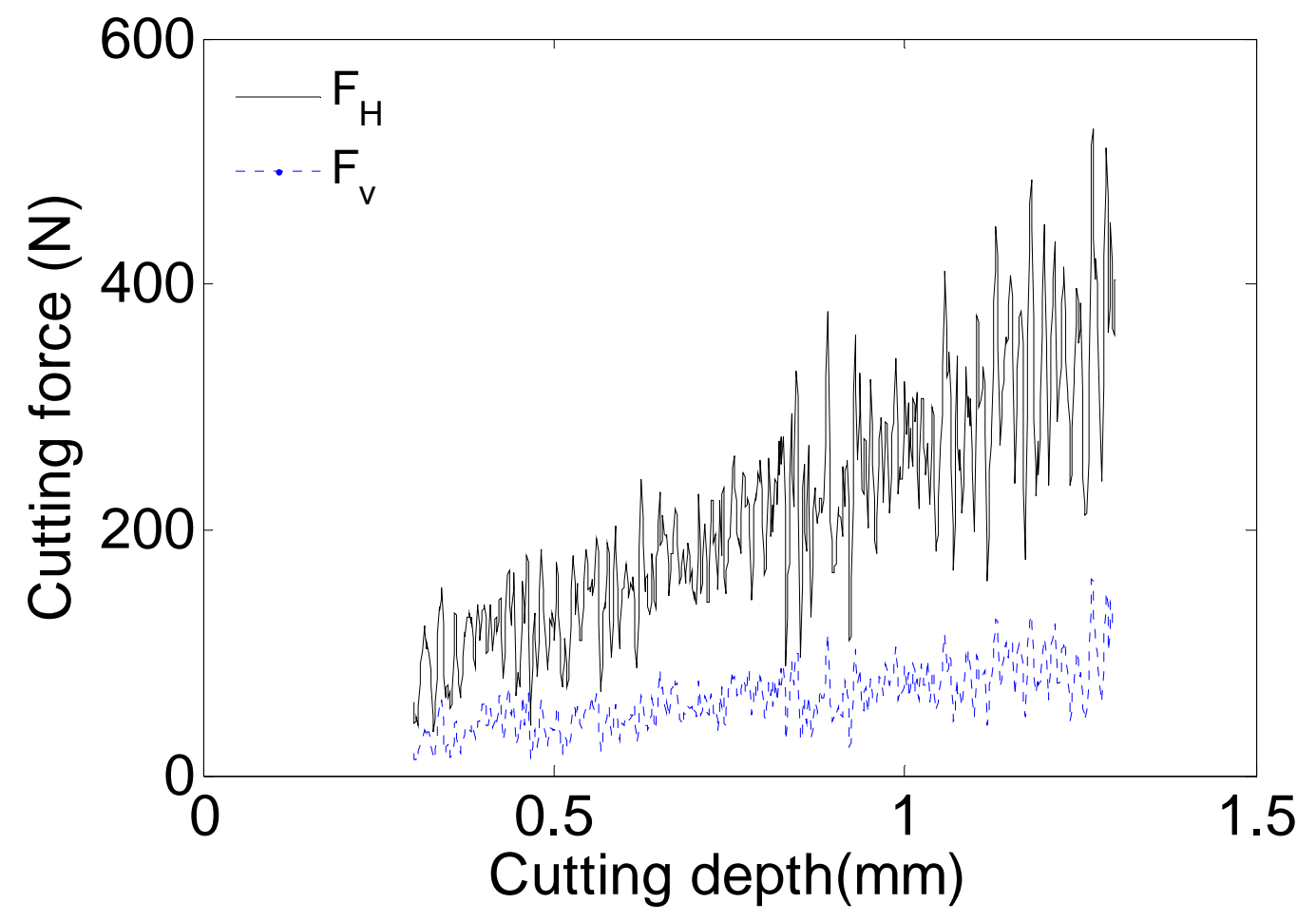

(b) The computed cutting forces

Figure 12 A linear orthogonal cut model for a PDC cutter (a) A snapshot of the failure/fragmentation pattern (b) The computed cutting forces (c) the computed mechanical specific energy of cutting. 


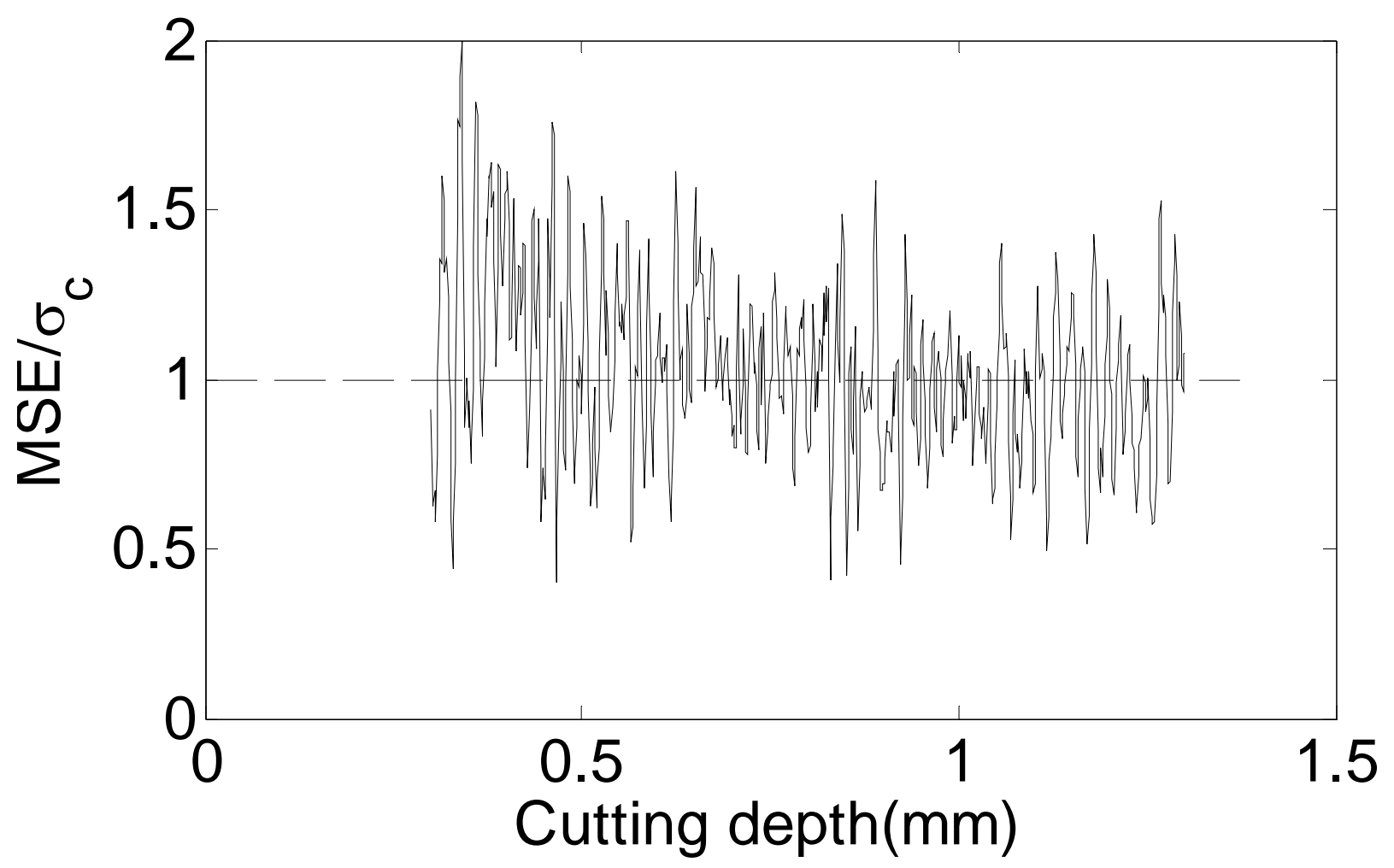

(c) the computed mechanical specific energy of cutting

Figure 12 (continued) 